\title{
The Incidence of Overdissipation in Rent-Seeking Contests
}

by

Michael R. Baye, The Pennsylvania State University

Dan Kovenock, Purdue University and The Tinbergen Institute

Casper G. deVries, Erasmus Universiteit Rotterdam and The Tinbergen Institute

January 1997 


\section{Introduction}

Gordon Tullock's seminal contribution in the area of rent-seeking, and wasteful overdissipation in particular, has not had the influence outside of Public Choice that it deserves. The purpose of this paper is to point out that even though his original analysis of overdissipation is technically flawed, the definition of overdissipation can be modified to explain instances in which rational rent-seekers spend more to win a prize than the prize is worth.

Specifically, since Tullock's seminal paper in 1967 most of the literature has focused on the degree to which the competition for rent dissipates that rent. While this literature extends across several fields ${ }^{1}$, it is concentrated to a large extent in the field of public choice ${ }^{2}$, where a standard tool in the theoretical analysis of rent-seeking is Tullock's rent-seeking game (1975, 1980). In this game, $\mathrm{n}$ risk-neutral players enjoy complete information and simultaneously submit nonnegative bids for a prize worth $\mathrm{Q}$ dollars. Letting $\left(\mathrm{x}_{1}, \ldots, \mathrm{x}_{\mathrm{n}}\right) \geq 0$ denote the bids of players 1 through $\mathrm{n}$, the probability player $\mathrm{i}$ wins the prize is given by

$$
p_{i}\left(x_{1}, \ldots, x_{n}\right)=\left\{\begin{array}{cl}
1 / n & \text { if } x_{1}=x_{2}=\ldots=x_{n}=0 \\
\frac{x_{i}^{R}}{\sum_{j=1}^{n} x_{j}^{R}} & \text { otherwise }
\end{array}\right.
$$

${ }^{1}$ See, for instance Posner (1975) and Fudenberg and Tirole (1987) in industrial organization, and Krueger (1974) and Bhagwati (1982) in international trade.

${ }^{2}$ See surveys by Brooks and Heijdra (1989), Nitzan (1994), or Rowley (1991). 
Hence, the payoff to player i from submitting a bid of $x_{i}$ when the other $n-1$ players submit bids of $x_{-i} \equiv\left(x_{1}, x_{2}, \ldots, x_{i-1}, x_{i+1}, \ldots x_{n}\right)$ is given by

$$
\mathrm{U}_{\mathrm{i}}\left(\mathrm{x}_{\mathrm{i}}, \mathrm{x}_{-\mathrm{i}}\right)=\mathrm{p}_{\mathrm{i}}\left(\mathrm{x}_{\mathrm{i}}, \mathrm{x}_{\mathrm{-}-\mathrm{i}}\right) \mathrm{Q}-\mathrm{x}_{\mathrm{i}} .
$$

Henceforth, we will refer to this symmetric, simultaneous-move game of complete information as the Tullock game.

By the end of the 1970s, two competing postulates emerged about rent-seeking games:

Posner's Rent Dissipation Postulate: In equilibrium, the total expenditures of rent-seekers equals the value of the prize.

Tullock's Rent Dissipation Postulate: In equilibrium, rent-seeking expenditures exceed the value of the prize when $R>n /(n-1)$.

Posner's postulate (1975) relies on a strong free-entry assumption: If existing rent-seekers were in the aggregate spending less than the value of the prize, their expected profits would be positive. This would induce entry by other rent-seekers until profits are driven to zero. Tullock's postulate is based on the Tullock game and his observation that when $R>n /(n-1)$, the sum of the solutions to each player's first order conditions exceeds the value of the prize Q. Tullock $(1980,1984,1985,1987,1989)$ devoted considerable attention to this possibility, presumably because of the strong implication for excessive social waste. ${ }^{3}$ Indeed, as R increased, the amount

${ }^{3}$ Tullock (1989) noted regarding the overdissipation result ... "when I demonstrated that perfect calculation leads to decidedly odd results even in a competitive market with free entry, I astonished myself." He went on to note that the original (1980) paper "was rejected by the Journal of Political Economy on the argument that it could not possibly be true that a competitive market would reach these results." In explaining why experiments run with MBA students for $\mathrm{n}=2$ and $\mathrm{R}=3$ did not yield overdissipation on average he reasoned "it is clear that the people concerned are not making correct calculations," and "it seems to me that ... these people do not 
of overdissipation would tend to infinity. A large literature emerged in an attempt to eliminate the apparent overdissipation of rents by altering the Tullock game. ${ }^{4}$ Contributions in this line of research include Corcoran (1984), Corcoran and Karels (1985), Higgins, et al. (1987), Michaels (1988), Allard (1988), Leininger (1993), Leininger and Yang (1994) and Nitzan (1991)).

It is now widely recognized (Hillman and Samet (1987), Baye, et al. (1989, 1993, 1994, 1996)) that expected overdissipation is not part of a Nash equilibrium to the Tullock game for any value of $\mathrm{R}$, even as $\mathrm{R}$ approaches infinity. The reason is that the Tullock game has a pure strategy Nash equilibrium if and only if $\mathrm{R} \leq \mathrm{n} /(\mathrm{n}-1)$. For $\mathrm{R}>\mathrm{n} /(\mathrm{n}-1)$ the symmetric solution to the players' first order conditions for expected payoff maximization does not yield a global maximum; at this solution players have a negative expected payoff, which is dominated by bidding zero. Thus, Tullock's postulate is based on a false premise.

In light of this, it is perhaps surprising that we demonstrate below that the overdissipation postulate for which Tullock is most frequently criticized can, in fact, be defended on theoretical grounds within the confines of his original model! The defense, it turns out, relies on the fact that when the Tullock parameter exceeds $\mathrm{n} /(\mathrm{n}-1)$ the Nash equilibrium involves mixedstrategies. Specifically, Baye, Kovenock, and de Vries (1994) show that equilibrium mixed strategies in the Tullock game do not permit overdissipation in expectation: the expected total

understand the game."

${ }^{4}$ In addition, numerous studies focus on the special case where $\mathrm{R}=1$ (see, for instance, Ellingsen (1991), Nitzan (1991), Paul and Wilhite (1991)). In this case, the solution to the firstorder conditions do indeed yield a Nash equilibrium, but there is not overdissipation in the corresponding equilibrium. 
amount spent competing for rents cannot exceed the value of the prize. ${ }^{5}$ However, since the equilibrium involves mixed-strategies, it turns out that for particular realizations of the mixed strategies the total amount spent competing for rents can exceed the value of the prize! In fact, we show below that the cross-sectional incidence of overdissipation may be quite high. For a symmetric perfectly discriminating contest $(\mathrm{R}=\infty)$, the probability of overdissipation in a symmetric equilibrium is roughly one-half, ranging from exactly one-half in the two player case to approximately .44 as the number of players approaches infinity.

The implication of this is straightforward: even when rent-seekers have complete information and are "perfect calculators," roughly one-half of the time they will spend more in the aggregate than the prize is worth. Roughly equally frequently they will, as a group, spend less than it is worth. This stochastic nature of the overdissipation of rents when $R>n /(n-1)$ is the conceptual innovation that we examine in Sections 2 and 3 of this paper. Given the ironic nature of this "defense" of the Tullock postulate -- ironic because Tullock criticizes mixedstrategies in his 1987 and 1995 comments -- we conclude with a discussion of the merits of his comments on our 1994 paper.

\section{Defining the Overdissipation of Rents.}

For the two player case, Tullock postulated that equilibrium entails the overdissipation of rents when $\mathrm{R}>2$. As we noted in the introduction, in this case the only Nash equilibria to the Tullock game are in nondegenerate mixed-strategies. For this reason, it is necessary to distinguish between the expected level of rent dissipation that arises based on the ex ante

${ }^{5}$ Baye, Kovenock and de Vries (1994) analyze the case of $n=2$ and $R>2$. The method of proof is similar for $n>2$ and $R>n /(n-1)$. 
strategies employed by players, and the level of rent dissipation that arises ex post (that is, for particular realizations of the strategies). In addition, it is useful to distinguish situations where the group as a whole spends more than the value of the prize (either in an ex ante or ex post sense) from those in which one or more individuals each spend more than the value of the prize. This gives rise to four alternative notions of the overdissipation of rents:

(EIO) Expected Individual Overdissipation occurs if an individual player's expected bid exceeds the value of the prize.

(EAO) Expected Aggregate Overdissipation occurs if the expected sum of the payments by the players exceeds the value of the prize.

(PIO) Probabilistic Individual Overdissipation occurs if there is a positive probability that an individual player bids more than the value of the prize.

(PAO) Probabilistic Aggregate Overdissipation occurs if there is a positive probability that the sum of all players' bids exceed the value of the prize.

The following result is immediate and shows the relation among these four definitions of overdissipation.

Proposition 1: For the Tullock game,

(a) $\mathrm{EIO} \Rightarrow \mathrm{EAO} \Rightarrow \mathrm{PAO}$;

(b) $\mathrm{EIO} \Rightarrow \mathrm{PIO} \Rightarrow \mathrm{PAO}$. 
Thus, for the Tullock game, the broadest of the definitions of overdissipation is PAO, and the most narrow is EIO. Notice that the contrapositive of Proposition 1 implies that if there is not probabilistic aggregate overdissipation, then there is not overdissipation in the other three senses either.

\section{Equilibrium Overdissipation in the Tullock Model?}

We begin with

Proposition 2: There do not exist equilibria to the Tullock game in which EAO, EIO, or PIO arise.

The formal proof of this proposition merely involves extending the results in Baye, Kovenock and de Vries (1994) from the two player case to the n-player case, and is thus omitted. The essential intuition can be seen by noting that a player can guarantee a payoff of at least zero by bidding zero. Hence, no equilibrium strategy can involve PIO, since bids above Q guarantee a negative payoff, and hence are strictly dominated. Similarly, no equilibrium can involve EIO because EIO requires PIO. Finally, since the above argument implies that $\mathrm{U}_{\mathrm{i}}\left(\mathrm{x}_{\mathrm{i}}, \mathrm{x}_{-\mathrm{i}}\right) \geq 0$ for every $i$, summing over all players and noting that the prize is awarded with probability one implies that no equilibrium can involve EAO. Furthermore, these arguments are valid for both pure and nondegenerate mixed-strategy equilibria.

Interestingly, however, the Tullock game does exhibit probabilistic aggregate overdissipation when R exceeds $\mathrm{n} /(\mathrm{n}-1)$ : 
Proposition 3: Suppose $\mathrm{R}>\mathrm{n} /(\mathrm{n}-1)$. Then in any Nash equilibrium to the Tullock game, PAO arises.

Proposition 3 follows directly from that fact that equilibria to the Tullock's original game involve non-degenerate mixed-strategies if $\mathrm{R}>\mathrm{n} /(\mathrm{n}-1)$. It indicates that an incidence of aggregate overdissipation is indeed possible in the original Tullock framework, but only in those instances where the equilibrium involves nondegenerate mixed-strategies and when one looks at aggregate ex post expenditures. To illustrate that the actual incidence of overdissipation due to PAO can be quite high, we use as a benchmark the perfectly discriminating (Hillman and Riley (1989)) or first-price all-pay auction (Baye et al. $(1989,1993,1996)$ ) version of the Tullock game. This game form is the limiting case of the Tullock game when $\mathrm{R}=\infty$; thus, the probability that player $\mathrm{i}$ wins the prize is one if player i submits the highest bid and zero otherwise. ${ }^{6}$ The $\mathrm{R}=\infty$ case is a useful benchmark because Baye, Kovenock, and de Vries (1993) have shown that at this level of $\mathrm{R}$ the expected level of rent dissipation is maximized. Furthermore, when $\mathrm{R}=\infty$ there is complete rent dissipation in the sense of EAO (the expected sum of the bids exactly equals the value of the prize).

Without loss of generality, suppose the value of the prize, Q, equals 1 . Hence the payoff to player $i$ as a function of the vector of bids of all $n$ players is

${ }^{6}$ In the case of a tie among $\mathrm{m}$ players for the highest bid, each has a probability $(1 / \mathrm{m})$ of winning the prize. 


$$
U_{i}\left(x_{1}, x_{2}, \ldots, x_{n}\right)=\left\{\begin{aligned}
-x_{i} & \text { if } \exists j \text { such that } x_{j}>x_{i} \\
\frac{1}{m}-x_{i} & \text { if } i \text { ties for high bid } \\
& \text { with } m-1 \text { others } \\
1-x_{i} & \text { if } x_{i}>x_{j} \forall j \neq i .
\end{aligned}\right.
$$

For $n=2$ the unique equilibrium of this game is symmetric (Hillman and Riley, 1989). For $n>2$ there is a continuum of asymmetric equilibria as well as a unique symmetric equilibrium (Baye, Kovenock and de Vries, 1996). We focus here on the symmetric mixed-strategy equilibrium, which involves players randomizing according to a continuous mixed strategy with associated cumulative distribution function $\mathrm{F}(\mathrm{x}) \equiv \mathrm{x}^{1 /(\mathrm{n}-1)}$ on $[0,1]$. This symmetric equilibrium fully dissipates rents in the sense of EAO, as do all of the asymmetric equilibria (Baye, Kovenock, and de Vries, 1996).

Since each player's bid is a random draw from $\mathrm{F}$ and the value of the prize is one, there cannot be overdissipation in the sense of either EAO, EIO, or PIO (this illustrates Proposition 2). However, notice that there is a positive probability that the sum of the realizations of the players' bids exceeds 1 , i.e. the assumed value of the prize.

To see this, let $\mathrm{z}=\mathrm{x}_{1}+\mathrm{x}_{2}+\ldots+\mathrm{x}_{\mathrm{n}}$ denote the sum of the bids. Notice that $\mathrm{z}$ is a random variable induced by the mixed strategies employed by the players, so let $G(Z)=\operatorname{Prob}\{z \leq Z\}$ be its cumulative distribution function. The probability of overdissipation is given by the probability that the sum of the bids exceeds unity, which is $\operatorname{Prob}\{z>1\}=1-\mathrm{G}(1)$. The 
symmetric Nash equilibrium mixed strategies imply that each $\mathrm{x}_{\mathrm{i}}$ has a density $\mathrm{f}\left(\mathrm{x}_{\mathrm{i}}\right)=\mathrm{ax}_{\mathrm{i}}{ }^{\mathrm{a}-1}$ on $[0,1]$, where $\mathrm{a} \equiv 1 /(\mathrm{n}-1)$. Hence,

$$
G(1)=a^{n} \int_{0}^{1} x_{n}^{a-1} \int_{0}^{1-x_{n}} x_{n-1}^{a-1} \cdots \int_{0}^{1-x_{n}-x_{n-1} \ldots-x_{2}} x_{1}^{a-1} d x_{1} d x_{2} \cdots d x_{n} .
$$

We now state the following general result:

Proposition 4. Suppose $\mathrm{R}=\infty$ and $\mathrm{n} \geq 2$ in the original simultaneous-move Tullock game. Then in any symmetric equilibrium we have PAO $\in[0.44,0.5]$. More specifically:

a. The probability of aggregate overdissipation is

$$
1-G(1)=1-\left(\frac{n-1}{n}\right)\left[\Gamma\left(\frac{n}{n-1}\right)\right]^{n-1} .
$$

where $\Gamma(t)=\int_{o}^{\infty} x^{t-1} e^{-x} d x$ is the Gamma function;

b. The probability of overdissipation is monotonically decreasing in the number of players;

c. The probability of overdissipation is maximized in the two player case in which the probability of overdissipation is exactly $1 / 2 ;^{7}$

d. In the limit as the number of players tends to infinity, the probability of overdissipation tends to $1-\mathrm{e}^{-\gamma} \approx .44$, where $\gamma$ is Euler's constant. ${ }^{8}$ Hence, the probability of overdissipation is bounded from below by .44 .

Proof: See the Appendix.

${ }^{7}$ For $n=3$ this probability is $1-\pi / 6 \approx 0.48$, while for $n=4$ it is approximately 0.466 .

${ }^{8}$ See Abramovitz and Stegun (1965). Formally, $\gamma$ is defined by

$$
\gamma=\lim _{h \rightarrow \infty}\left[1+\frac{1}{2}+\frac{1}{3}+\cdots+\frac{1}{h}-\log h\right] \text {. }
$$


Proposition 4 makes it clear that Tullock's postulate is, in a sense, correct: in the aggregate, rent-seekers may frequently spend more to win a prize than the prize is worth. This result helps explain why PAO is confirmed in some of the published experimental literature (cf. Millner and Pratt, 1989, 1990) as well as informal experiments we have run at Tilburg University, Erasmus University, Penn State, Purdue, Texas A\&M University, and the New Economic School in Moscow. The theoretical and empirical literatures can be reconciled because when $\mathrm{R}>\mathrm{n} /(\mathrm{n}-1)$, equilibria of the Tullock game involve nondegenerate mixed-strategies.

\section{Other Rent-Seeking Contests}

It is of interest to apply our new definitions of overdissipation to other types of contests. This will also make it clear why it is useful to make a distinction between individual and aggregate overdissipation.

Consider, for instance, the (stationary) symmetric equilibrium of the two person symmetric war of attrition, which is equivalent to a second-price all-pay auction. Assume that the value of the prize and the cost to each player per unit of time spent fighting both equal one, and that there is no discounting. Each player's symmetric equilibrium strategy in this game is mixed and is represented by the cdf, $G(t)=1-e^{-t}$. This gives the probability that the player stops fighting before $t$. In the interpretation as an all-pay auction it is the probability the player bids below $t$. The game ends at the minimum realized stopping time. The time elapsed equals the cost incurred by each player. Hence, the distribution of the cost incurred by each player fighting for the prize is the distribution of the minimum order statistic $\mathrm{G}_{\min }(\mathrm{t})=1-[1-\mathrm{G}(\mathrm{t})]^{2}=1-\mathrm{e}^{-2 \mathrm{t}}$, which also gives the distribution of the game's termination time. 
The expected payoff to each player in this equilibrium is zero. Since each player incurs a cost of 1 per unit of time until the game ends, if the game stops after $t=1 / 2$, the aggregate cost of the contest will exceed the value of the prize; overdissipation will arise. Hence, PAO characterizes the symmetric equilibrium. Aggregate overdissipation occurs with probability $1-\mathrm{G}_{\min }(1 / 2)=\mathrm{e}^{-1} \approx .368$, which is lower than in the first-price all-pay auction.

The war of attrition, unlike the first-price all-pay auction, also has the property that the probability of overdissipation by a single player is nonzero, i.e. PIO is also a property of the symmetric equilibrium. In this equilibrium, if the game ends after $\mathrm{t}=1 \underline{\text { each }}$ player's individual cost is greater than the value of the prize. This event has probability $1-\mathrm{G}_{\min }(1)=\mathrm{e}^{-2} \approx .135$.

This makes it clear that Tullock's original postulate is, in a way, correct; every individual player can make payments that are greater than the value of the prize. Individual overdissipation, however, cannot occur in the game Tullock examined (in which all players pay their own bids) or in the manner Tullock described (ex ante expectation).

Another rent-seeking contest in which it is possible for individual players to make payments greater than the value of the prize is the sad-loser auction. In this auction each player i simultaneously bids $\mathrm{x}_{\mathrm{i}}$. The highest bidder wins the prize (of value 1) and is refunded her bid. The remaining bidders forfeit their bids.

This type of auction might be viewed as a reduced-form for situations, such as contests for procurement contracts, in which the bids represent pre-award (prototype) development costs, and the winning bidder can recoup these costs under the terms of the contract. In the two bidder case the individual players' symmetric equilibrium bidding strategies are $\mathrm{G}(\mathrm{x})=\mathrm{x} /(1+\mathrm{x})$, which has an unbounded mean. Each player earns a zero payoff in expectation. The aggregate payment 
in the game is the minimum order statistic, which has a distribution $\mathrm{G}_{\min }(\mathrm{x})=1-[1 /(1+\mathrm{x})]^{2}$. Hence the probability of aggregate overdissipation is $1-\mathrm{G}_{\min }(1)=1 / 4$. Since only the loser pays, this is also the probability that there is individual overdissipation by some player. Hence, PIO and thus also PAO characterize the symmetric equilibrium to this game.

Like the first price all-pay auction, the war of attrition and the sad loser auction are contests with complete information. Of course, if we allow for incomplete information it should not seem surprising that overdissipation is possible, and that the probability of overdissipation will depend on the distributional assumptions maintained when transforming the game to one of complete, but imperfect information in which types are chosen by nature. Due to the lack of a clear benchmark model, we omit a formal analysis at this stage.

\section{Reply to Tullock}

Gordon Tullock has done the profession a great service by pointing to the need to understand how institutions affect the wasteful expenditure of resources on rent seeking. The purpose of this section is to reply to some of the comments Tullock has published (cf Tullock, 1987, 1989, 1995) on papers that provide solutions to questions raised in his original paper (cf Hillman and Samet, 1987; Baye, Kovenock and de Vries, 1994).

Like a good lawyer, Gordon Tullock knows that if you can't win the game you're playing you have to find another game to play. This is his basic approach in his critique of our and earlier papers that examine the Tullock postulate. Briefly, in Baye, Kovenock and de Vries (1994) we show that when individuals have the chance to opt out of a game and receive a payoff of zero (by spending zero), then no Nash equilibrium in the Tullock game can yield an individual 
an expected payoff of less than zero. In turn, this implies that overdissipation cannot occur in expectation, either individually or in the aggregate.

When confronted with a proof that, on average, there is no overdissipation of rents in any Nash equilibrium of his game, Tullock's strategy is to write comments that either (1) attack the game form, or (2) challenge the mixed-strategy solution concept. Importantly, we showed in Section 3 above that these tactics are unnecessary: the aggregate incidence of overdissipation can be quite high in those situations (and only those situations) where the equilibrium is in mixed-strategies!

\section{A. The Game Form.}

Four of the issues raised by Tullock's (1995) comment involve changing the game form appearing in Baye, Kovenock and de Vries (1994). Specifically, Tullock suggests changing the game to permit (1) An exogenous sequencing of moves, (2) risk aversion, (3) "entry," and (4) different currencies . Obviously, changing the structure of a game can change the equilibrium. Our "solution" is relevant for Tullock's original simultaneous move game with complete information and risk-neutral players; we merely took as given the move-structure, risk neutrality, and information specified in Tullock's original paper. Tullock's response to the answer we provide in our (1994) paper is to change the question!

\section{i. Sequencing of Moves}

Specifically, we focused on a simultaneous move setting because this is the movestructure specified in Tullock's original formulation of the problem. We recognize that this specification is not innocuous; it has been well-known since Stackelberg that games with an exogenous sequencing of moves can yield outcomes that differ from simultaneous move games. 
Contrary to the claims of Tullock (1995) this is not merely an issue of pure versus mixed strategies. Sequential and simultaneous move games are different games. The issue that arises, however, is what determines the sequencing of moves. The issue of endogenous sequencing of moves has been thoroughly addressed in the industrial organization literature by Daughety and Reinganum (1994) Deneckere and Kovenock (1992), and Hamilton and Slutsky (1990), among others. These methods have been applied by Leininger and Yang (1994) to analyze the endogenous sequencing of moves in rent-seeking games. One lesson from this literature is that in order to obtain an endogenous sequencing one often must utilize a rather unnatural game form in which, either by brute-force alternating sequencing or by allowing players to precommit not to move in a period, simultaneous moves are avoided. Whether one prefers the endogenous sequencing or simultaneous move approach is then often a matter of taste in game forms. Regardless, moving from a simultaneous to sequential move setting will not lead to the overdissipation of rents in the sense of EAO or EIO.

\section{ii. Risk Aversion}

We also recognize that equilibrium is sensitive to the assumed risk-preferences of players. Our sole motivation for assuming risk-neutrality was because that was the assumption made in Tullock's original formulation. Our methods can easily be extended to analyze rent-seeking games with utility concave in money, as in Skaperdas and Gan (1995). Tullock's point that a player might want to deviate from a mixed strategy solution in order to bankrupt an opponent (see Tullock (1995, p. 26)) involves changing the preferences of players in the game. Tullock's original formulation does not assume that players derive utility from bankrupting their opponents. Obviously, if one changes Tullock's original payoff functions to include a cost of 
bankruptcy (or a benefit to bankrupting the opponent), the solution will change. We do not purport to offer a solution for arbitrary specifications of player preferences, but rather a solution to the game where preferences are as originally specified by Tullock. Regardless, risk-aversion alone cannot lead to overdissipation in expectation, and one might reasonably expect risk aversion to reduce the probability that aggregate overdissipation occurs in a mixed-strategy equilibrium.

\section{iii. Entry}

Tullock also suggests changing the game to allow a previous entry stage. We did not formally analyze an entry game because Tullock's original game treats the number of players as fixed. However, logic similar to that in our 1994 paper implies that there will never exist overdissipation in a Nash equilibrium in the sense of EAO or EIO. It is well-known from work on entry in industrial organization that entry costs can yield underdissipation of rent in expectation. Mixed strategy equilibria at the entry stage or exogenous uncertainty can lead to overdissipation in the sense of PIO or PAO.

\section{iv. Currency}

Tullock also proposes changing the game to allow players to make expenditures in different currencies. This proposed change, as it turns out, does not materially affect the nature of the game, provided one properly interprets the modified game. In particular, the original Tullock game (and thus our solution) assumes a common unit of account. Thus, $\mathrm{x}_{1}$ and $\mathrm{x}_{2}$ denote expenditures in dollars, say. Notice that if player 1 is an American and player 2 a German, a dollar payment of $x_{2}$ by the German is, in terms of DM, $x_{2}{ }^{*} \equiv \lambda x_{2}$, where $\lambda$ is the exchange rate. Similarly, if the prize is $\mathrm{Q}$ dollars, the $\mathrm{DM}$ equivalent value of the prize is $\mathrm{Q}^{*} \equiv \lambda \mathrm{Q}$ to the 
German. Thus, it follows that the equilibrium we derived for the case where prizes are denominated in dollars is still an equilibrium in the case of different currencies, provided the German can convert DM into dollars and vice versa at an exchange rate that is common knowledge to all players. For this same reason, our focus on the case where $\mathrm{Q}=1$ is without loss of generality as well.

\section{B. The Solution Concept}

In light of the results in Section 3, we believe Tullock should reassess his distaste for mixed-strategy Nash equilibria. There are well-reasoned justifications of mixed-strategy Nash equilibria appearing in the literature (see, for instance, Brandenburger (1992)). For those like Tullock who are searching for a justification for overdissipation, it would seem that a powerful rationale for using mixed-strategies is that they can generate an incidence of overdissipation. ${ }^{9}$ Otherwise, Tullock must not only propose an alternative solution concept for his game, but an alternative justification for the overdissipation of rents. Mixed strategies, as it turns out, provide both the needed solution concept as well as a defense for the Tullock postulate.

In concluding, we note that there are solution concepts that can rationalize overdissipation in expectation. For instance, it is possible to find rationalizable strategies that yield overdissipation in expectation. However, these strategy choices cannot constitute a Nash equilibrium and, hence, if the choices or conjectures generating them were mutual knowledge, at least one player would not be playing rationally. Likewise, overdissipation in expectation can arise in $\epsilon$-equilibria to the Tullock game. However, when Gordon Tullock (1989) claims that the

${ }^{9}$ Recent work by Che and Gale (1996) shows that the symmetric equilibrium mixedstrategies that we identify are identical to the pure strategy bidding functions that arise when rentseekers face budget constraints and incomplete information about the size of rivals' budgets. 
theory of efficient rent seeking is "based on the theory that people are perfect calculators," and dismisses experimental work for relying on the computational ability of MBA students who clearly "are not making correct calculations," it is clear that he has a Nash-like consistency requirement in mind. Section 3 above shows that incidences of aggregate overdissipation are not at odds with Nash consistency. Tullock's postulate is indeed correct: perfectly rational individuals might spend more, in the aggregate, competing for a prize than it is worth. But Tullock was right for the wrong reason. 


\section{REFERENCES}

Abramovitz, M. and I. Stegun (New York: Dover), Handbook of Mathematical Functions, 1970.

Allard, R. J. "Rent-Seeking with non-identical players," Public Choice, 57, 1988, 3-14.

Baye, M. R., D. Kovenock and C. G. de Vries, "Rigging the Lobbying Process: An Application of the All-Pay Auction," American Economic Review, 83, March 1993, pp. 289-294.

Baye, M. R., D. Kovenock and C. G. de Vries, "The all-pay auction with complete information," Economic Theory, 8, 1996, pp. 291-305.

Baye, M. R., D. Kovenock and C. G. de Vries, "The Economics of All-Pay, Winner-Take-All, Contests," Texas A\&M University Working Paper 89-21, 1989.

Baye, M. R., D. Kovenock and C. G. de Vries, "The Solution to the Tullock Rent-Seeking Game when R > 2: mixed-strategy equilibria and mean dissipation rates, Public Choice, 81, 1994, pp. 363-380.

Bhagwati, N. J., "Directly unproductive profitseeking (DUP) activities," Journal of Political Economy, 90, 1982, 988-1002.

Brandenburger, A., "Knowledge and Equilibrium in Games," Journal of Economic Perspectives, 6, 1992, pp. 83-102.

Brooks, M. and B. Heydra, "An Exploration of Rent Seeking," Economic Record, 65, 1989.

Che, Y. and I. Gale, "Financial Constraints in Auctions: Effects and Antidotes," Advances in Applied Microeconomics 6, 1996, pp. 97-120.

Corcoran, W., "Long-run equilibrium and total expenditures in rent-seeking," Public Choice, 43, 1984, 89-94.

Corcoran, W. and G. Karels, "Rent-seeking behavior in the long-run," Public Choice, 1985, 227247.

Daughety, A. and J. Reinganum, "Asymmetric Information Acquisition and Behavior in Role Choice Models: an Endogenously Generated Signaling Game," International Economic Review 35 (1994), 793-819.

Deneckere, R. and D. Kovenock, "Price Leadership," Review of Economic Studies 59 (1992), pp. 143-162. 
Ellingsen, T., "Strategic buyers and the social cost of monopoly," American Economic Review, 1991, 648-657.

Fudenberg, D. and O. Tirole, "Understanding rent dissipation: on the use of game theory in industrial organization," AEA Papers and Proceedings, 77, 1987, 176-183.

Hamilton, J. H. and Slutsky, S. M., "Endogenous Timing and Duopoly Games: Stackelberg or Cournot Equilibria," Games and Economic Behavior 2 (1990), pp. 29-46.

Higgins, R., W. Shughart and R. Tollison, "Free entry and efficient rent-seeking," Public Choice, $46,1985,247-258$.

Hillman, A. and J. Riley, "Politically contestable rents and transfers," Economics and Politics, $1989,17-39$.

Hillman A. and D. Samet, "Dissipation of contestable rents by small numbers of contenders," Public Choice, 1987, 63-82.

Krueger, A., "The political economy of the rent-seeking society," American Economic Review, 64, 1974, 291-303.

Leininger, W., "More efficient rent-seeking: a Münchhausen solution," Public Choice, 75, 1993, pp. $43-62$.

Leininger, W. and C. Yang, "Dynamic rent-seeking games," Games and Economic Behavior, 7, 1994, pp. 406-427.

Michaels, R., "The design of rent-seeking competitions," Public Choice, 56, 1988, 17-29.

Millner, E. L. and Pratt, M. D., (1989), "An experimental investigation of efficient rent-seeking," Public Choice 62: 139-151.

Millner, E. L. and Pratt, M. D., (1990), "Risk aversion and rent-seeking: An extension and some experimental evidence," Public Choice 69, pp. 81-92.

Nitzan, S. "Collective rent dissipation," Economic Journal, 101, 1991, 1522-1534.

Nitzan, S., "Modeling rent-seeking contests," European Journal of Political Economy, 10, 1994, 41-60.

Paul, C. and A. Whilhite, "Rent-seeking, rent-defending, and rent-dissipation," Public Choice, 1991, 61-70. 
Posner, R., "The social costs of monopoly and regulation," Journal of Political Economy, 83, 1975, 807-27.

Rowley, C., "Gordon Tullock: Entrepreneur of public choice," Public Choice, 71, 1991, 149169.

Skaperdas, S. and L. Gan, "Risk Aversion in Contests," Economic Journal (1995), pp. 951-962.

Tullock, G., "The welfare costs of tariffs, monopolies and theft," Western Economic Journal, 5, 1967, 224-232.

Tullock, G., "On the efficient organization of trials," Kyklos, 28, 1975, 745-762.

Tullock, G., "Efficient rent-seeking," in: J. M. Buchanan, R. Tollison, and G. Tullock, eds., Toward a theory of the rent-seeking society, (College Station: Texas A\&M University Press), 1980, 97-112.

Tullock, G., "Long-run-equilibrium and total expenditures in rent-seeking: A comment," Public Choice, 1984, 95-97.

Tullock, G., "Back to the bog," Public Choice, 1985, 259-263.

Tullock, G., "Another part of the swamp," Public Choice, 1987, 83-84.

Tullock, G., "Editorial comment," Public Choice, 1989, 153-154.

Tullock, G., "The reluctant games person -- A comment on Baye, Kovenock and de Vries," Public Choice, 85, 1995, pp. 189-192. 


\section{APPENDIX}

To evaluate the multiple integral in equation (1) of the text, we use the following lemma:

Lemma A1: Let $\phi(w) \equiv \int_{0}^{1-w} x^{r}(1-w-x)^{s} d x$. Then $\phi(\mathrm{w})=(1-\mathrm{w})^{\mathrm{r}+\mathrm{s}+1} \beta(\mathrm{r}+1, \mathrm{~s}+1)$, where $\beta(r+1, s+1) \equiv \int_{0}^{1} x^{r}(1-x)^{s} d x$ is the Beta function.

Proof:

$$
\begin{aligned}
\phi(w) & \equiv \int_{0}^{1-w} x^{r}(1-w-x)^{s} d x \\
& =(1-w)^{r+s+1} \int_{0}^{1} t^{r}(1-t)^{s} d t \\
& =(1-w)^{r+s+1} \beta(r+1, s+1)
\end{aligned}
$$

by the change of variable $\mathrm{t}=\mathrm{x} /(1-\mathrm{w})$. Q.E.D.

\section{Proof of Proposition 4:}

(a) Applying the Lemma (taking $\mathrm{w}=1-\mathrm{x}_{\mathrm{n}}-\mathrm{x}_{\mathrm{n}-1}-\ldots-\mathrm{x}_{2}, \mathrm{r}=\mathrm{a}-1, \mathrm{~s}=0$, and $\mathrm{x}=\mathrm{x}_{1}$ ) gives us

$$
G(1)=a^{n} \int_{0}^{1} x_{n}^{a-1} \int_{0}^{1-x_{n}} x_{n-1}^{a-1} \cdots \int_{0}^{1-x_{n}-\cdots-x_{3}} x_{2}^{a-1}\left(1-x_{1}-\cdots-x_{2}\right)^{a} \beta(a, 1) d x_{2} d x_{3} \cdots d x_{n} .
$$

Again, using the Lemma (taking $\mathrm{w}=1-\mathrm{x}_{1}-\ldots-\mathrm{x}_{3}, \mathrm{r}=\mathrm{a}-1, \mathrm{~s}=\mathrm{a}$, and $\mathrm{x}=\mathrm{x}_{2}$ ) gives

$$
G(1)=a^{n} \beta(a, 1) \beta(a, a+1) \int_{0}^{1} x_{n}^{a-1} \cdots \int_{0}^{1-x_{n}-\cdots-x_{4}} x_{3}^{a-1}\left(1-x_{1}-\cdots-x_{3}\right)^{2 a} d x_{3} \cdots d x_{n},
$$

and with $\mathrm{w}=1-\mathrm{x}_{1}-\ldots-\mathrm{x}_{4}, \mathrm{r}=\mathrm{a}-1, \mathrm{~s}=2 \mathrm{a}$, and $\mathrm{x}=\mathrm{x}_{3}$,

$$
G(1)=a^{n} \beta(a, 1) \beta(a, a+1) \beta(a, 2 a+1) \int_{0}^{1} x_{n}^{a-1} \cdots \int_{0}^{1-x_{n}-\cdots-x_{3}} x_{4}^{a-1}\left(1-x_{n}-\cdots-x_{4}\right)^{3 a} d x_{4} \cdots d x_{n} .
$$

Continuing in this fashion we obtain

$$
\begin{aligned}
G(1) & =a^{n} \beta(a, 1) \beta(a, a+1) \beta(a, 2 a+1) \beta(a, 3 a+1) \cdots \int_{0}^{1} x_{n}^{a-1}\left(1-x_{n}\right)^{(n-1) a} d x_{n} \\
& =a^{n} \beta(a, 1) \beta(a, a+1) \beta(a, 2 a+1) \beta(a, 3 a+1) \cdots \beta(a,(n-1) a+1) .
\end{aligned}
$$


Note that $\beta(\mathrm{a}, \mathrm{b})=\frac{\Gamma(a) \Gamma(b)}{\Gamma(a+b)}$, where $\Gamma(t)=\int_{0}^{\infty} x^{t-1} e^{-x} d x$ is the Gamma function. Hence ${ }^{10}$,

$$
\begin{aligned}
G(1) & =a^{n} \frac{\Gamma(a) \Gamma(1)}{\Gamma(a+1)} \frac{\Gamma(a) \Gamma(a+1)}{\Gamma(2 a+1)} \frac{\Gamma(a) \Gamma(2 a+1)}{\Gamma(3 a+1)} \ldots \frac{\Gamma(a) \Gamma((n-1) a+1)}{\Gamma(n a+1)} \\
& =\frac{a^{n}[\Gamma(a)]^{n}}{\Gamma(n a+1)}=\frac{[a \Gamma(a)]^{n}}{\Gamma(n a+1)}=\frac{[\Gamma(a+1)]^{n}}{\Gamma(n a+1)}=\left(\frac{1}{a+1}\right)[\Gamma(a+1)]^{n-1} .
\end{aligned}
$$

Using the definition of $a$ gives the form in equation (2) of the text.

(b) To establish monotonicity, let $\mathrm{P}(\mathrm{x})=\operatorname{Prob}\left\{\sum \mathrm{x}_{\mathrm{i}} \leq 1\right\}=\frac{1}{1+x}[\Gamma(1+x)]^{1 / x}$,

where $x \in[0,1], x=1 /(n-1)$, and $\mathrm{n}-1$ denotes number of opponents. It is sufficient to show

that $\mathrm{P}(\mathrm{x})$ is monotonic in $\mathrm{x}$. Taking logs gives

$$
\log \mathrm{P}(\mathrm{x})=-\log (1+\mathrm{x})+\frac{1}{x} \log \Gamma(1+\mathrm{x}) .
$$

Differentiating this expression yields

$$
\frac{d \log P(x)}{d x}=-\frac{1}{1+x}-\frac{1}{x^{2}} \log \Gamma(1+x)+\frac{1}{x} \psi(x+1)
$$

where $\psi$ is the Psi (or Digamma) function (see Abramowitz and Stegun, 1965). Limiting values are obtained by l' Hôpital's rule:

$$
\begin{gathered}
\left.\frac{1}{x^{2}}[\log \Gamma(1+x)-x \psi(1+x)]\right|_{x=0}= \\
\left.\frac{\psi(1+x)-\psi(1+x)-x \psi^{\prime}(1+x)}{2 x}\right|_{x=0}= \\
-\left.\frac{1}{2} \psi^{\prime}(1+x)\right|_{x=0}=-\frac{1}{2} \psi^{\prime}(1)<0
\end{gathered}
$$

${ }^{10}$ In these calculations we make use of the identities $\Gamma(t+1)=t \Gamma(t)$ and $\Gamma(n+1)=n !$, for $t$ positive real and $\mathrm{n}$ positive integer valued. 
Hence

$$
\begin{gathered}
\left.\frac{d \log P(x)}{d x}\right|_{x=0}=-1-\frac{1}{2} \Psi^{\prime}(1) \approx-1.82<0 \\
\left.\frac{d \log P(x)}{d x}\right|_{x=1}=-\frac{1}{2}-[\log \Gamma(2)-\psi(2)]=-\frac{1}{2}-[0-.42]=-.08<0 .
\end{gathered}
$$

To evaluate the intermediate values we write

$$
\frac{d \log P(x)}{d x}=\frac{1}{x^{2}}\left\{-\frac{x^{2}}{1+x}-\log \Gamma(1+x)+x \psi(1+x)\right\}
$$

and analyze the sign of the terms within the curled brackets on the interval $(0,1)$. Differentiating the term in brackets yields

$$
\begin{gathered}
-\frac{2 x}{1+x}+\frac{x^{2}}{(1+x)^{2}}-\psi(1+x)+\psi(1+x)+x \Psi^{\prime}(1+x)= \\
\left.x \Psi^{\prime}(1+x)+\frac{x^{2}-2 x-2 x^{2}}{(1+x)^{2}}\right]= \\
x\left[\psi^{\prime}(1+x)-\frac{2+x}{(1+x)^{2}}\right]= \\
x\left[\psi^{\prime}(1+x)-\frac{1}{1+x}-\frac{1}{(1+x)^{2}}\right]
\end{gathered}
$$

We can concentrate on the term inside the last pair of square brackets, and write $y=1+x$, $y \in(1,2)$, so that the derivative of the bracketed term becomes:

$$
\psi^{\prime}(y)-\frac{1}{y}-\frac{1}{y^{2}}
$$

We will show that this term does not change sign as $n \geq 2$ increases. Toward this end, note that 


$$
\psi^{\prime}(y) \equiv \int_{0}^{\infty} \frac{t e^{-y t}}{1-e^{-t}} d t
$$

Now from the Taylor expansion of the exponential

$$
\begin{gathered}
\frac{1}{1-e^{-t}}=\frac{e^{t}}{e^{t}-1}=\frac{1+t+t^{2} / 2+t^{3} / 6+\ldots}{t+t^{2} / 2+t^{3} / 6+\ldots}= \\
1+\frac{1}{t+t^{2} / 2+t^{3} / 6+\ldots}
\end{gathered}
$$

Hence, for $\mathrm{t} \geq 0$ :

$$
\frac{t}{1-e^{-t}}=t+\frac{1}{1+t / 2+t^{2} / 6+\ldots} \leq t+\frac{1}{1+t / 2} \leq t+1
$$

Thus

$$
\begin{aligned}
\Psi^{\prime}(y) & <\int_{0}^{\infty}(t+1) e^{-y t} d t \\
& =\int_{0}^{\infty} t e^{-y t} d t+\int_{0}^{\infty} e^{-y t} d t \\
& =\frac{1}{y} \int_{0}^{\infty} t y e^{-y t} d t+\frac{1}{y} \int_{0}^{\infty} y e^{-y t} d t \\
& =\frac{1}{y^{2}}+\frac{1}{y}
\end{aligned}
$$

and therefore

$$
\psi^{\prime}(y)-\frac{1}{y}-\frac{1}{y^{2}} \leq 0 .
$$

Now the proof of monotonicity of $\mathrm{P}(\mathrm{x})$ for $\mathrm{x} \in[0,1]$ is complete as

$$
\frac{d \log \mathrm{P}(x)}{d x}=\frac{1}{x^{2}} f(x)
$$

where $\mathrm{f}(\mathrm{x})$ is the expression between curled brackets in (A1). At the end points

$$
f(0)=0, f(1)=-0.08<0
$$

while the above analysis showed 


$$
f^{\prime}(x)<0 \text { on }(0,1] \text { and } f^{\prime}(0)=0
$$

Combining these gives

$$
f(x)<0 \text { on }(0,1]
$$

Moreover,

$$
1 / x^{2}>0 \text { on }(0,1]
$$

so that

$$
\frac{d \log P(x)}{d x}=\frac{1}{x^{2}} f(x)<0 \text { on }(0,1]
$$

Hence $\log \mathrm{P}(\mathrm{x})$ is decreasing on $(0,1]$. Incidently, note that

$$
\begin{aligned}
& \log P(0)=\psi(1)=\gamma \approx-.57 \\
& \log P(1)=-\log 2 \approx-.69
\end{aligned}
$$

(c) This part follows directly from part (b).

(d) Setting $\mathrm{h}=\mathrm{n}-1$, it follows that

$$
\lim _{h \rightarrow \infty} \log \left[\Gamma\left(1+\frac{1}{h}\right)\right]^{h}=\lim _{h \rightarrow \infty}\left[\log \Gamma\left(1+\frac{1}{h}\right)\right] /(1 / h),
$$

which by l' Hôpital's rule equals

$$
\left.\lim _{h \rightarrow \infty}\left(\frac{\partial \Gamma(z)}{\partial z} / \Gamma(z)\right)\right|_{z=1+\frac{1}{h}}
$$

The expression $\frac{\partial \Gamma(z)}{\partial z} / \Gamma(z)$ is the Psi or Digamma function (see Abramowitz and Stegun (1965)) which, when evaluated at $\mathrm{z}=1$ is equal to $-\gamma$, where $\gamma \approx .5772$ is Euler's constant. Hence, as $\mathrm{h}$ (and hence $\mathrm{n}$ ) goes to infinity

$$
G(1)=\lim _{h \rightarrow \infty}\left(\frac{h}{h+1}\right)\left[\Gamma\left(\frac{h+1}{h}\right)\right]^{h}=e^{-\gamma} \approx .5615 .
$$


Hence, in the limit, the probability of overdissipation is approximately 0.4385 . 